\title{
Biopsy-Proven Kidney Involvement in Hypocomplementemic Urticarial Vasculitis
}

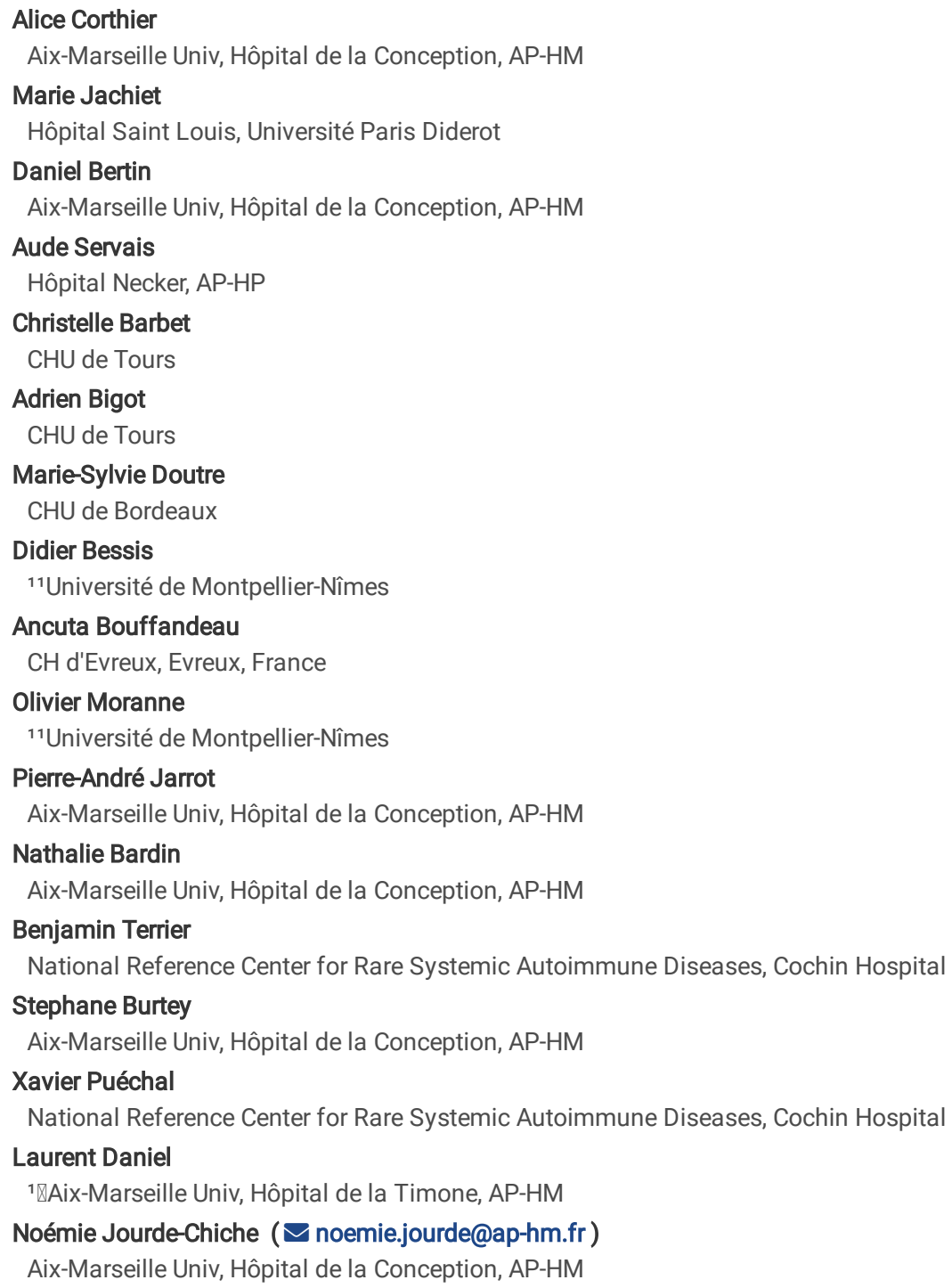

\section{Research Article}

Keywords: Vasculitis, Hypocomplementemic urticarial vasculitis, Kidney disease, Acute kidney injury, Kidney biopsy, Anti-C1q antibodies

Posted Date: May 18th, 2021

DOI: https://doi.org/10.21203/rs.3.rs-471283/v1

License: (9) (7) This work is licensed under a Creative Commons Attribution 4.0 International License. Read Full License 


\section{Abstract}

Background. Hypocomplementemic urticarial vasculitis (HUV) is a rare systemic vasculitis. We aimed to describe the kidney involvement of HUV in a multicenter national cohort with an extended follow-up.

Methods. All patients with HUV (international Schwartz criteria) with a biopsy-proven kidney involvement, identified through a survey of the French Vasculitis Study Group, were included. A systematic literature review on kidney involvement of HUV was performed.

Results. Twelve patients were included, among whom 8 had positive anti-C1q antibodies. All presented with proteinuria, from mild to nephrotic, and 8 displayed acute kidney injury (AKI), requiring temporary haemodialysis in 2. Kidney biopsy showed membrano-proliferative glomerulonephritis (GN) in 8 patients, pauci-immune crescentic GN or necrotizing vasculitis in 3 patients (with a mild to severe interstitial inflammation), and an isolated interstitial nephritis in 1 patient. C1q deposits were observed in the glomeruli $(n=6)$, tubules $(n=4)$ or renal arterioles $(n=3)$ of 8 patients. All patients received corticosteroids, and 9 were also treated with immunosuppressants or apheresis. After a mean follow-up of 8.9 years, 6 patients had a preserved renal function, but 2 patients had developed stage 3-4 chronic kidney disease (CKD) and 4 patients had reached end-stage kidney disease (ESKD), among whom 1 had received a kidney transplant.

Conclusion. Renal involvement of HUV can be responsible for severe AKI, CKD and ESKD. It is not always associated with circulating anti-C1q antibodies. Kidney biopsy shows mostly membrano-proliferative $\mathrm{GN}$ or crescentic $\mathrm{GN}$, with frequent $\mathrm{C} 1 \mathrm{q}$ deposits in the glomeruli, tubules or arterioles.

\section{Key Messages}

- Kidney involvement in HUV can be life-threatening and lead to end-stage kidney disease.

- Glomerular, vascular and tubulo-interstitial compartments can be injured, with frequent C1q deposits.

- Systematic screening for kidney involvement during flares of HUV could accelerate diagnosis and treatment and reduce kidney damage.

\section{Background}

Hypocomplementemic urticarial vasculitis (HUV) is a rare systemic vasculitis, also called "McDuffie syndrome" or "anti-C1q vasculitis". It was classified among immune complex small vessel vasculitides in the revised international Chapel Hill consensus conference in 2012 (1). It was first described by McDuffie et al in 1973 and then well defined in 1982 by Schwartz et al $(2,3)$. They proposed diagnostic criteria composed of 2 major criteria (recurrent urticarial lesions for at least 6 months and hypocomplementemia) associated with 2 minor criteria among the following: leukocytoclastic vasculitis (on cutaneous biopsy), arthralgia or arthritis, glomerulonephritis, ocular inflammation (uveitis or episcleritis), recurrent abdominal pain or anti-C1q antibody positivity. The frequency of kidney involvement associated with HUV ranges from 14-50\% across different cohorts, and is poorly defined (4-6). In the French national cohort published in 2015 by Jachiet et al (5), a kidney involvement of HUV was observed in 10 (18\%) patients, but detailed pathological lesions were not available. In addition, little is known on the long-term prognosis of kidney involvement in HUV, and no specific therapeutic strategy is defined in the literature. We describe here the clinical presentation, the pathological lesions and the therapeutic management of a multicentre cohort of 12 patients with biopsy-proven kidney involvement associated with HUV, identified through the French Vasculitis Study Group (FVSG) network.

\section{Methods}

This is a multicentre retrospective study, conducted in accordance with the principles of the Declaration of Helsinki. All cases of patients with HUV, as defined by Schwartz criteria, and a biopsy-proven kidney involvement, identified through a survey sent to physicians from the French Study Group on Vasculitis network, were reviewed and included. Some of these patients were included in the national cohort by Jachiet et al.

The following data was collected for each patient: demographic characteristics, systemic symptoms, skin lesions, adenopathy, rheumatic, ocular, eyes nose throat, lung, gastrointestinal, neurologic, cardiac involvement, and detailed renal parameters. AKI was defined according to the RIFLE criteria as R (risk), I (injury) and F (failure) (7). Serum levels of C-reactive protein, complement fractions C3 and C4, anti-C1q antibodies, antinuclear antibodies (ANA), antiphospholipid antibodies, rheumatoid factor, cryoglobulinemia, anti-neutrophil cytoplasmic antibodies (ANCA) and protein electrophoresis were collected. All patients were tested for immunization against hepatitis B, C, HIV and syphilis. Results of skin biopsies were collected when available. All patients had at least one kidney biopsy, analysed by light microscopy and immunofluorescence. Electronic microscopy description was reported when available. The therapeutic strategies, global outcome and renal outcome were collected. Chronic kidney disease (CKD) was defined as a permanently altered kidney function with an estimated glomerular filtration rate (eGFR) $<60 \mathrm{~mL} / \mathrm{min} / 1.73 \mathrm{~m}^{2}$ using the MDRD formula (8).

We then performed a systematic literature review on cases of HUV with renal involvement, using the following MESH terms: Hypocomplementemic urticarial vasculitis, Mac Duffie, kidney/renal involvement, acute kidney injury, chronic kidney disease, glomerulonephritis and kidney/renal biopsy.

For statistical analysis, continuous variables were compared using the Wilcoxon-Mann-Whitney test on mean or median values; categorical variables were compared using the Fisher's exact test.

\section{Results}


Twelve patients with a biopsy-proven kidney involvement of HUV were identified, of whom 6 were previously included in the cohort of Jachiet et al. Their clinical and biological characteristics are detailed in Table 1. Two patients had a paediatric onset of HUV. Chronic urticarial lesions were present in all patients. Arthralgia were reported in 8 patients, with clinical arthritis in 3, and lymphadenopathies in 5 patients. Five patients displayed ocular involvement of HUV: anterior uveitis in 3 patients, conjunctivitis in 2, retinal involvement in two. Pulmonary symptoms (recurrent bronchitis) were described by 3 patients, among whom 1 had chronic respiratory failure. One patient displayed a pericarditis. Anti-C1q antibodies were positive in 8 patients. ANA were detected in 7 patients, among whom one had anti-SSA and anti-double stranded DNA antibodies (patient \#12), and another had anti-SSA antibodies and positive cryoglobulinemia (patient \#7). ANCA antibodies were detected in 6 patients, among whom 3 had anti-myeloperoxidase (MPO) antibodies, 1 anti-proteinase 3 (PR3) antibodies, and 2 no antigenic specificity.

\section{Renal involvement of HUV}

All patients presented with proteinuria, from mild to nephrotic. Eight patients presented with acute kidney injury (AKI), requiring temporary hemodialysis in 2 patients. One patient had stage R, 5 stage I and 3 stage F AKI. Pathological examination of kidney is detailed in Table 2 for the 12 patients, among whom 2 had a repeat biopsy. Kidney lesions were various, with different patterns of glomerular, vascular, and tubulo-interstitial involvements (Figure 1). A membranoproliferative GN was documented in 8 patients, with crescents in 7, and with a full-house immunofluorescence pattern in 1 patient. Four patients had active vascular lesions: 2 had a necrotizing vasculitis (patients \#2 and \#11), and 2 had immune deposits of IgG, IgM, C3 and C1q in vascular walls (patient \#2 and \#9). One patient (\#12) had an isolated interstitial nephritis without glomerular or vascular changes. The second biopsies of patients \#2 and \#7 showed consistent glomerular and vascular patterns, with different levels of inflammatory and fibrotic lesions. The second biopsy of patient \#9 showed severe chronic lesions and glomerulosclerosis. Electron microscopy analysis was performed in 2 patients. It showed, in patient \#4, abundant and diffuse electron-dense segmental subepithelial and subendothelial granular deposits in capillary walls; in the second biopsy of patient \#7, few glomerular electron-dense granular deposits.

\section{Treatment and outcome}

Corticosteroids were prescribed in all patients, for all renal flares of HUV, as shown in Figure 2A. Corticosteroids were tapered and continued for several years in some patients. An additional immunosuppressive therapy was prescribed in 9 patients. Rituximab was used in $5 / 12$ patients ( 1 as a first line therapy, 3 after corticosteroids, 1 after cyclophosphamide). It allowed a remission in 4 patients (patient \#9, with severe AKI initially requiring dialysis, was not in remission at last follow-up), and was reinfused successfully in 2 patients who relapsed. Patients were followed-up for an average of 8.9 years. The detailed evolution of patients is described in Figure $\mathbf{3}$ and Supplementary Figure 1. The total number of renal flares per patient ranged from 1 to 8 . An infectious trigger for renal relapses was documented in 2 patients (one with pneumococcal pneumonia, and one with several relapses occurring after viral or bacterial infections). Plasma exchanges were used in 2 patients from this cohort: patient \#2, for a relapse of HUV with severe AKI, which required also successively mycophenolate mofetil, cyclophosphamide and rituximab; and patient \#9, for persistent severe AKI with massive proteinuria despite corticosteroids and rituximab. Patient \#2 reached ESKD 2 years later, after an unplanned pregnancy, and received a kidney transplant without further relapse of HUV. Her second pregnancy was carriedout normally while she was transplanted, without HUV relapse.

At last follow-up, all patients were alive. Patient \#2 had received a kidney transplant, patients \#3 and \#7 were on chronic dialysis, patient \#9 had stage 5 CKD, patients \#2 and \#10 had stage 3A CKD. The other 6 patients had a preserved eGFR $\left(\geq 60 \mathrm{~mL} / \mathrm{min} / 1.73 \mathrm{~m}^{2}\right)$ without proteinuria. A severe complication of immunosuppressive therapy had occurred in 2 patients (one bacterial pneumonia and one cryptococcal meningitis).

\section{Kidney involvement of HUV in the literature}

Case reports of kidney involvement of HUV from the literature were collected and compared to patients from the present cohort (Table 3) (9-31). The clinical presentation of the 26 patients with kidney involvement of HUV from the literature was consistent with the present work but high blood pressure was more frequent at diagnostic in our cohort $(p=0.005)$. The broad range of kidney lesions observed in the present cohort was also observed in the literature. Cryoglobulinemia and ANCAs antibodies were more frequent in our cohort (respectively $p=0.002$ and 0.02$)$ and the follow-up was longer ( $p=0.002$ ). Out of these 26 patients, 5 died, 4 reached ESKD and 2 developed stage 3 CKD.

Treatments administered to the patients from the literature are detailed in Figure 2B. Two patients with kidney involvement received rituximab as a third line therapy: the first patient experienced a full recovery of kidney function after 12 months of dialysis dependence (31), the second was a child without available data on outcome (24). Plasma exchanges were used in 2 patients from this cohort but were not sufficient and required additional treatment with rituximab or cyclophosphamide. Only 2 patients from the literature were treated with plasma exchanges for AKI (1 reached ESKD, the other reached remission) (13,22).

Considering both the present cohort and patients from the literature (total $n=38$ ), the presence of anti-C1q antibodies was not associated with outcomes: $41 \%$ of patients with positive anti-C1q had an unfavourable outcome (ESKD or death) versus $33 \%$ of patients without antiC1q ( $p=0.74$ ).

\section{Discussion}

This is the first study describing specifically biopsy-proven kidney involvement of HUV, with detailed pathological data and long term follow-up. We show that HUV can be associated with different glomerular lesions (mainly membrano-proliferative GN, but also crescentic GN, with or without immune glomerular deposits), lesions of renal arterioles (both acute and chronic, sometimes with C1q and immune complex deposits), and tubulo-interstitial inflammation (sometimes with tubular C1q and immune complex deposits). Notably, at the time of kidney biopsy, the interstitial fibrosis was often absent or mild, suggesting a rapid and recent occurrence of renal lesions. This kidney involvement can be life-threatening, with AKI requiring emergency dialysis, and can lead 
to ESKD. Yet, even with a severe initial presentation, a complete renal recovery can be obtained with corticosteroids, and possibly immunosuppressive therapy, in a majority of patients.

HUV is an immune-complex mediated systemic vasculitis affecting small vessels (1). Immune complex deposits in vessel walls are usually documented on skin biopsies of urticarial lesions, and we show here that these deposits, comprising C1q, can also be encountered in renal arterioles.

Yet, immune deposits are not systematic in the kidney of patients with HUV, especially in glomeruli, were pauci-immune forms of crescentic GN can be encountered. An overlap between HUV and ANCA-associated vasculitis (AAV) could be discussed in these patients. Here, among the 6 patients with positive ANCA antibodies, only 4 had specific ANCA, among whom 3 displayed membrano-proliferative GN (classically not encountered in AAV) and only 1 displayed pauci-immune CGN. This last patient, indeed, both responded to HUV classification criteria (chronic urticaria, complement consumption, arthralgia, glomerulonephritis, and anti-C1q antibodies) and displayed features of AAV (arthralgia, glomerulonephritis and anti-MPO antibodies).

Similarly, the possible overlap between HUV and systemic lupus erythematosus can be discussed in patients with positive ANA. Among the 7 patients with positive, only 1 had anti-dsDNA, and displayed isolated interstitial nephritis. Only 1 patient with positive ANA displayed a membrano-proliferative GN with fullhouse immune deposits. Apart from this kidney involvement, this patient had no specific feature of lupus but displayed: biopsy-proven cutaneous leucocytoclastic vasculitis, angioedema, and recurrent bronchitis with chronic respiratory failure.

HUV is a rare disease, but its exact incidence is unknown (6). Kidney involvement of HUV is even more rare: in the largest retrospective cohort of HUV, comprising 57 cases gathered in France over 20 years, 10 (18\%) patients displayed kidney involvement of HUV (5). In an American cohort comprising 18 patients with HUV, 9 (50\%) patients displayed kidney involvement (4). More recently, a Swedish cohort of 16 patients reported 5 patients with kidney involvement, among whom 2 reached ESKD (6). Membrano-proliferative GN, membranous GN, minimal change disease, focal glomerulopathy and antiglomerular basement membrane nephritis have been described in the literature (32). We confirm in this work the heterogeneity of clinical presentation and kidney pathological lesions in patients with HUV.

AntiC1q antibodies are IgG antibodies directed against the collagen-like region of C1q. They are encountered in HUV and in other diseases associated with immune complex deposition, such as mixed connective tissue disorder, systemic lupus erythematosus and post-infectious vasculitis (5). The presence of antiC1q antibodies has been associated with kidney involvement in lupus, and more specifically with crescentic lesions (33). The presence of anti-C1q antibodies was only a minor criterion in Schwartz et al (2), but was considered more discriminant in the revised international Chapel Hill consensus conference of 2012 (1). However, the specificity and sensitivity of anti-C1q antibodies are unknown. Their presence is neither sufficient nor mandatory to diagnose HUV: $67 \%$ of patients from the present cohort, and $38 \%$ of patients from the literature had positive anti-C1q antibodies. In the French retrospective cohort by Jachiet et al, $55 \%$ of HUV patients had positive anti-C1q antibodies and $90 \%$ had a low $\mathrm{C} 1 \mathrm{q}$, and $88 \%$ from the American cohort by Wisnieski et al had positive anti-C1q antibodies. The prognostic value of anti-C1q antibodies in HUV is controversial: it was associated with renal involvement in the French cohort by Jachiet et al, but showed no prognostic value for the global outcome (ESKD or death) in the present cohort and in the literature review of patients with kidney involvement.

The treatment of HUV and of its kidney involvement is far from established. While corticosteroids were used in all patients from the present cohort, Rituximab was used mostly as a 2nd or 3rd line therapy, but could be proposed as a corticoid-sparing agent in relapsing forms of HUV.

We underline the value of repeat kidney biopsy in these patients, which can allow the differentiation of active versus chronic renal lesions and guide the need for immunosuppressive regimen.

\section{Conclusion}

Patients with HUV can display heterogeneous kidney lesions with glomerular, vascular and tubulo-interstitial involvement, with or without immune complex deposits. Kidney involvement of HUV can be severe and relapsing, and lead to ESKD. Corticosteroids, and Rituximab in severe forms, could be the preferential therapeutic options. Screening for proteinuria, and monitoring of blood pressure and serum creatinine could be proposed in all patients with HUV followed-up in Rheumatology or Dermatology, at the time of the diagnosis and during subsequent flares, to diagnose and treat kidney lesions early to avoid chronic kidney damage.

\section{Abbreviations}

AKI: acute kidney injury

ANA: anti-nuclear antibodies

ANCA: anti-neutrophil cytoplasmic antibodies

CKD: chronic kidney disease

ESKD: end-stage kidney disease

GN: glomerulonephritis

HUV: hypocomplemtemic urticarial vasculitis

MPO: myeloperoxidase 
PR3: proteinase 3

\section{Declarations}

Ethics approval and consent to participate: this study was conducted in accordance with the principles of the Declaration of Helsinki. All methods were carried out in accordance with relevant guidelines and regulations. The experimental design was approved by the relevant licensing committee in France, the CNIL (Commission Nationale Informatique et Liberté), with the approval number 2019_104.

Consent for publication: not applicable, only the authorization of the CNIL being required according to the French legislation for the publication of patient data collected retrospectively and anonymously.

Disclosure statement: the authors have no conflict of interest to declare.

Availability of data and material: the datasets used and/or analysed during the current study are available from the corresponding author on reasonable request.

Funding: no funding was received for this work.

Authors' contributions: $\mathrm{AC}$ acquired the data and wrote the manuscript with NJC. MJ, AS, CB, AB, MSD, DiB, AB, OM contributed to collect data on patients' cases. DaB, NB contributed on laboratory data extraction. BT, XP contributed on patient recruitment through the FVSG network. LD was responsible for renal pathological interpretation. All authors read the final manuscript and approved it.

Acknowledgements: we thank Alain Vazi and Laurent Samson for their help with the serum biobank.

\section{References}

1. Jennette JC, Falk RJ, Bacon PA, Basu N, Cid MC, Ferrario F, et al. 2012 revised International Chapel Hill Consensus Conference Nomenclature of Vasculitides. Arthritis Rheum. 2013 Jan;65(1):1-11.

2. McDuffie FC, Sams WM, Maldonado JE, Andreini PH, Conn DL, Samayoa EA. Hypocomplementemia with cutaneous vasculitis and arthritis. Possible immune complex syndrome. Mayo Clin Proc. 1973 May;48(5):340-8.

3. Schwartz HR, McDuffie FC, Black LF, Schroeter AL, Conn DL. Hypocomplementemic urticarial vasculitis: association with chronic obstructive pulmonary disease. Mayo Clin Proc. 1982 Apr;57(4):231-8.

4. Wisnieski JJ, Baer AN, Christensen J, Cupps TR, Flagg DN, Jones JV, et al. Hypocomplementemic urticarial vasculitis syndrome. Clinical and serologic findings in 18 patients. Medicine (Baltimore). 1995 Jan;74(1):24-41.

5. Jachiet M, Flageul B, Deroux A, Le Quellec A, Maurier F, Cordoliani F, et al. The clinical spectrum and therapeutic management of hypocomplementemic urticarial vasculitis: data from a French nationwide study of fifty-seven patients. Arthritis Rheumatol Hoboken NJ. 2015 Feb;67(2):527-34.

6. Sjöwall C, Mandl T, Skattum L, Olsson M, Mohammad AJ. Epidemiology of hypocomplementaemic urticarial vasculitis (anti-C1q vasculitis). Rheumatology. 2018 Aug 1;57(8):1400-7.

7. Bellomo R, Ronco C, Kellum JA, Mehta RL, Palevsky P. Acute renal failure - definition, outcome measures, animal models, fluid therapy and information technology needs: the Second International Consensus Conference of the Acute Dialysis Quality Initiative (ADQI) Group. Crit Care. 2004;8(4):R204-12.

8. Levey AS, Bosch JP, Lewis JB, Greene T, Rogers N, Roth D. A more accurate method to estimate glomerular filtration rate from serum creatinine: a new prediction equation. Modification of Diet in Renal Disease Study Group. Ann Intern Med. 1999 Mar 16;130(6):461-70.

9. Meyrier A, Français P, Lesavre P, Mougenot B, Ronco P, Jeanmougin M, et al. [Hypocomplementemic urticarial vasculitis with glomerulopathy and renal venulitis]. Nephrologie. 1984;5(1):1-7.

10. Ramirez G, Saba SR, Espinoza L. Hypocomplementemic vasculitis and renal involvement. Nephron. 1987;45(2):147-50.

11. Kobayashi S, Nagase M, Hidaka S, Arai T, Ikegaya N, Hishida A, et al. Membranous nephropathy associated with hypocomplementemic urticarial vasculitis: report of two cases and a review of the literature. Nephron. 1994;66(1):1-7.

12. Mituiki K, Hirakata H, Oochi N, Nagashima A, Onoyama K, Abe M, et al. [Nephrotic syndrome due to membranous glomerulopathy in hypocomplementemic urticarial vasculitis syndrome;-a case report]. Nihon Jinzo Gakkai Shi. 1994 Jul;36(7):863-70.

13. Trendelenburg M, Courvoisier S, Späth PJ, Moll S, Mihatsch M, Itin P, et al. Hypocomplementemic urticarial vasculitis or systemic lupus erythematosus? Am J Kidney Dis Off J Natl Kidney Found. 1999 Oct;34(4):745-51.

14. Cadnapaphornchai MA, Saulsbury FT, Norwood VF. Hypocomplementemic urticarial vasculitis: report of a pediatric case. Pediatr Nephrol Berl Ger. 2000 Apr;14(4):328-31.

15. Sessler R, Hasche G, Olbricht CJ. [Hypocomplementemic urticarial vasculitis syndrome]. Dtsch Med Wochenschr 1946. 2000 Aug 25;125(34-35):1003-6.

16. Boulay V, Lauque D, Reynaud F, Carles P, Pourrat J. [Hypocomplementemic urticarial vasculitis]. Presse Medicale Paris Fr 1983. 2000 Sep 23;29(27):15079.

17. Messiaen T, Van Damme B, Kuypers D, Maes B, Vanrenterghem Y. Crescentic glomerulonephritis complicating the course of a hypocomplementemic urticarial vasculitis. Clin Nephrol. 2000 Nov;54(5):409-12.

18. Grimbert P, Schulte K, Buisson C, Desvaux D, Baron C, Pastural M, et al. Renal transplantation in a patient with hypocomplementemic urticarial vasculitis syndrome. Am J Kidney Dis Off J Natl Kidney Found. 2001 Jan;37(1):144-8. 
19. el Maghraoui A, Abouzahir A, Mahassine F, Tabache F, Bezza A, Ghafir D, et al. [McDuffie hypocomplementemic urticarial vasculitis. Two cases and review of the literature]. Rev Med Interne. 2001 Jan;22(1):70-4.

20. Saeki T, Ueno M, Shimada H, Nishi S, Imai N, Miyamura S, et al. Membranoproliferative glomerulonephritis associated with hypocomplementemic urticarial vasculitis after complete remission of membranous nephropathy. Nephron. 2001 Jun;88(2):174-7.

21. Enríquez R, Sirvent AE, Amorós F, Pérez M, Matarredona J, Reyes A. Crescentic membranoproliferative glomerulonephritis and hypocomplementemic urticarial vasculitis. J Nephrol. 2005 Jun;18(3):318-22.

22. Balsam L, Karim M, Miller F, Rubinstein S. Crescentic glomerulonephritis associated with hypocomplementemic urticarial vasculitis syndrome. Am J Kidney Dis Off J Natl Kidney Found. 2008 Dec;52(6):1168-73.

23. Abdallah M, Darghouth S, Hamzaoui S, Ben Ahmed M, Harmel A, Ennafaa M, et al. [McDuffie hypocomplementemic urticarial vasculitis associated with Sjögren's syndrome]. Rev Med Interne. 2010 Jul;31(7):e8-10.

24. Ozçakar ZB, Yalçınkaya F, Altugan FS, Kavaz A, Ensari A, Ekim M. Hypocomplementemic urticarial vasculitis syndrome in three siblings. Rheumatol Int. 2013 Mar;33(3):763-6.

25. Al Mosawi ZSA, Al Hermi BEA. Hypocomplementemic Urticarial Vasculitis Syndrome in an 8-year-old Boy: A Case Report and Review of Literature. Oman Med J. 2013 Jul;28(4):275-7.

26. Pasini A, Bracaglia C, Aceti A, Vivarelli M, Lavacchini A, Miniaci A, et al. Renal involvement in hypocomplementaemic urticarial vasculitis syndrome: a report of three paediatric cases. Rheumatol Oxf Engl. 2014 Aug;53(8):1409-13.

27. Park C, Choi SW, Kim M, Park J, Lee JS, Chung HC. Membranoproliferative glomerulonephritis presenting as arthropathy and cardiac valvulopathy in hypocomplementemic urticarial vasculitis: a case report. J Med Case Reports. 2014;8:352.

28. Tanaka M, Moniwa N, Mita T, Tobisawa T, Matsumoto T, Mochizuki A, et al. A Case of Crescentic Glomerulonephritis Complicated with Hypocomplementemic Urticarial Vasculitis Syndrome and ANCA-Associated Vasculitis. Case Rep Nephrol Dial. 2017 Dec;7(3):144-53.

29. Gheerbrant H, Giovannini D, Falque L, Andry F, Lugosi M, Deroux A. [Severe membranoproliferative glomerulonephritis with polyadenopathy associated with hypocomplementemic urticarial vasculitis syndrome]. Presse Medicale Paris Fr 1983. 2017 May;46(5):547-50.

30. Jung SW, Choi YY, Choi IS, Kim S, Jeong KH, Song R, et al. Hypocomplementemic Urticarial Vasculitis Syndrome with Membranous Nephropathy: Case Report. J Korean Med Sci. 2017 Dec;32(12):2064-8.

31. Salim SA, Yousuf T, Patel A, Fülöp T, Agarwal M. Hypocomplementemic Urticarial Vasculitis Syndrome With Crescentic Glomerulonephritis. Am J Med Sci. 2018 Feb;355(2):195-200.

32. Potlukova E, Kralikova P. Complement Component C1q and Anti-C1q Antibodies in Theory and in Clinical Practice. Scand J Immunol. 2008 May 1;67(5):423-30.

33. Jourde-Chiche N, Daniel L, Chiche L, Burtey S, Mancini J, Jego S, et al. Association between anti-C1q antibodies and glomerular tuft necrosis in lupus nephritis. Clin Nephrol. 2012 Mar;77(3):211-8.

\section{Tables}

Table 1: Clinical and biological presentation of the 12 patients from the present cohort. 


\begin{tabular}{|c|c|c|c|c|c|c|c|c|c|c|c|c|}
\hline & $\begin{array}{l}\text { Patient } \\
1\end{array}$ & $\begin{array}{l}\text { Patient } \\
2\end{array}$ & $\begin{array}{l}\text { Patient } \\
3\end{array}$ & $\begin{array}{l}\text { Patient } \\
4\end{array}$ & $\begin{array}{l}\text { Patient } \\
5\end{array}$ & $\begin{array}{l}\text { Patient } \\
6\end{array}$ & $\begin{array}{l}\text { Patient } \\
7\end{array}$ & $\begin{array}{l}\text { Patient } \\
8\end{array}$ & $\begin{array}{l}\text { Patient } \\
9\end{array}$ & $\begin{array}{l}\text { Patient } \\
10\end{array}$ & $\begin{array}{l}\text { Patient } \\
11\end{array}$ & $\begin{array}{l}\text { Patient } \\
12\end{array}$ \\
\hline Age at kidney involvement & 42 & 12 & 41 & 40 & 41 & 5 & 44 & 56 & 55 & 76 & 45 & 43 \\
\hline Gender & $\mathrm{F}$ & $\mathrm{F}$ & $\mathrm{F}$ & $\mathrm{F}$ & $\mathrm{F}$ & M & $\mathrm{F}$ & $\mathrm{F}$ & $\mathrm{F}$ & M & $\mathrm{F}$ & $\mathrm{F}$ \\
\hline
\end{tabular}

\section{Extra-renal involvement}

\begin{tabular}{|c|c|c|c|c|c|c|c|c|c|c|c|c|}
\hline Asthenia/fever & $+/+$ & $+/+$ & $+/-$ & $+/-$ & $+/-$ & $-/+$ & $+/-$ & $-/-$ & $-1-$ & $+/+$ & $+/+$ & $+/-$ \\
\hline Chronic urticaria & + & + & + & + & + & + & + & + & + & + & + & + \\
\hline Angioedema/purpura/livedo & $-/+/+$ & $-/-/-$ & $-/+/-$ & $+/-/-$ & $+/-/-$ & $-/-/-$ & $+/-/-$ & $-/-/-$ & $+/-/-$ & $-/+/-$ & $-/-/-$ & $-/-/-$ \\
\hline $\begin{array}{l}\text { Cutaneous leucocytoclastic } \\
\text { vasculitis* }\end{array}$ & + & - & + & + & + & ND & - & + & ND & + & ND & + \\
\hline Arthralgia/arthritis & $+/+$ & $+/+$ & $+/-$ & $-/-$ & $+/+$ & $-/-$ & $+/-$ & $-/-$ & $+/-$ & $+/-$ & $-/-$ & $+/-$ \\
\hline $\begin{array}{l}\text { Anterior } \\
\text { uveitis/conjunctivitis }\end{array}$ & $+/+$ & $-/+$ & $-/-$ & $-/-$ & $+/-$ & $-/-$ & $-/-$ & $-/-$ & $-/-$ & $-/-$ & $-/-$ & $+/-$ \\
\hline Retinopathy & + & - & - & - & - & - & - & + & - & - & - & - \\
\hline Lymphadenopathy & + & - & - & - & + & - & + & - & + & - & - & + \\
\hline $\begin{array}{l}\text { PRESS/peripheral } \\
\text { neuropathy }\end{array}$ & $+/-$ & $+/-$ & $-/-$ & $-/-$ & $-/-$ & $-/-$ & $-/-$ & $-/-$ & $-/-$ & $-/$ & $-/-$ & $-/-$ \\
\hline Respiratory disease & - & + & - & + & - & - & - & + & - & - & - & - \\
\hline Pericarditis & + & - & - & - & - & - & - & - & - & - & - & - \\
\hline
\end{tabular}

\section{Renal presentation :}

$\begin{array}{llllllllllll}\begin{array}{l}\text { Time since first symptoms } \\ \text { of HUV (months) }\end{array} & 84 & 22 & 37 & 55 & 49 & 42 & 60 & 0,5 & 76 & 0\end{array}$
of HUV (months)

\begin{tabular}{|c|c|c|c|c|c|c|c|c|c|c|c|c|}
\hline Proteinuria & + & + & + & + & + & + & + & + & + & + & + & + \\
\hline Nephrotic syndrome & + & - & + & + & - & + & + & - & + & - & - & - \\
\hline $\begin{array}{l}\text { Microscopic/macroscopic } \\
\text { haematuria }\end{array}$ & $+/-$ & $-/-$ & $+/+$ & $+/+$ & $-/-$ & $+/+$ & $+/+$ & $+/-$ & $+/+$ & $+/-$ & $-/-$ & $+/-$ \\
\hline Serum creatinine $(\mu \mathrm{mol} / \mathrm{L})$ & 225 & 703 & 325 & 90 & 71 & ND & 160 & 77 & 326 & 608 & 268 & 140 \\
\hline AKI & + & + & + & - & - & - & + & - & + & + & + & + \\
\hline Hemodialysis at diagnosis & - & + & - & - & - & - & - & - & - & + & - & - \\
\hline High blood pressure & + & + & - & - & - & - & + & + & + & + & - & + \\
\hline Pathological diagnosis & MPGN & MPGN & MPGN & MPGN & MPGN & MPGN & MPGN & MPGN & PI CGN & PI CGN & NV & IN \\
\hline \multicolumn{13}{|l|}{ Biology : } \\
\hline Elevated CRP & + & ND & ND & ND & ND & ND & ND & - & + & + & + & + \\
\hline Low C3 & + & + & + & + & + & + & + & + & ND & + & ND & + \\
\hline Low C4 & + & + & + & + & + & + & + & + & + & + & ND & + \\
\hline Low CH50 & + & + & + & + & + & + & ND & + & ND & + & ND & + \\
\hline Low C1q & + & + & + & ND & + & ND & ND & ND & + & + & ND & + \\
\hline Anti-C1q antibody & + & ND & + & - & + & ND & + & + & + & - & + & + \\
\hline Antinuclear antibody & - & + & - & + & - & - & + & + & + & - & + & + \\
\hline Antiphospholipid antibody & - & - & ND & - & ND & ND & ND & ND & ND & - & + & ND \\
\hline Rheumatoid factor & + & - & - & - & - & - & - & ND & ND & - & - & + \\
\hline Cryoglobulinemia & + & - & - & - & - & - & + & + & ND & + & - & + \\
\hline ANCA (anti-MPO/anti-PR3) & - & $\stackrel{+}{(+/-)}$ & - & - & - & - & $\stackrel{+}{(+/-)}$ & $+(-/+)$ & $+(+/-)$ & - & $+(-/-)$ & $+(-/-)$ \\
\hline
\end{tabular}

Monoclonal gammapathy

PRESS: Posterior reversible encephalopathy syndrome, AKI: acute kidney injury, CRP: C-reactive protein, ANCA: anti-neutrophil cytoplasmic antibodies, F: female, M: male, ND: not determinate, +: positive, -: negative, MPGN: membrano proliferative glomerulo nephritis, PI CGN: pauci-immune crescentic 
glomerulonephritis, NV: necrotizing vasculitis, IN: interstitial nephritis.

Table 2: Kidney pathological findings in the 12 patients from the present cohort.

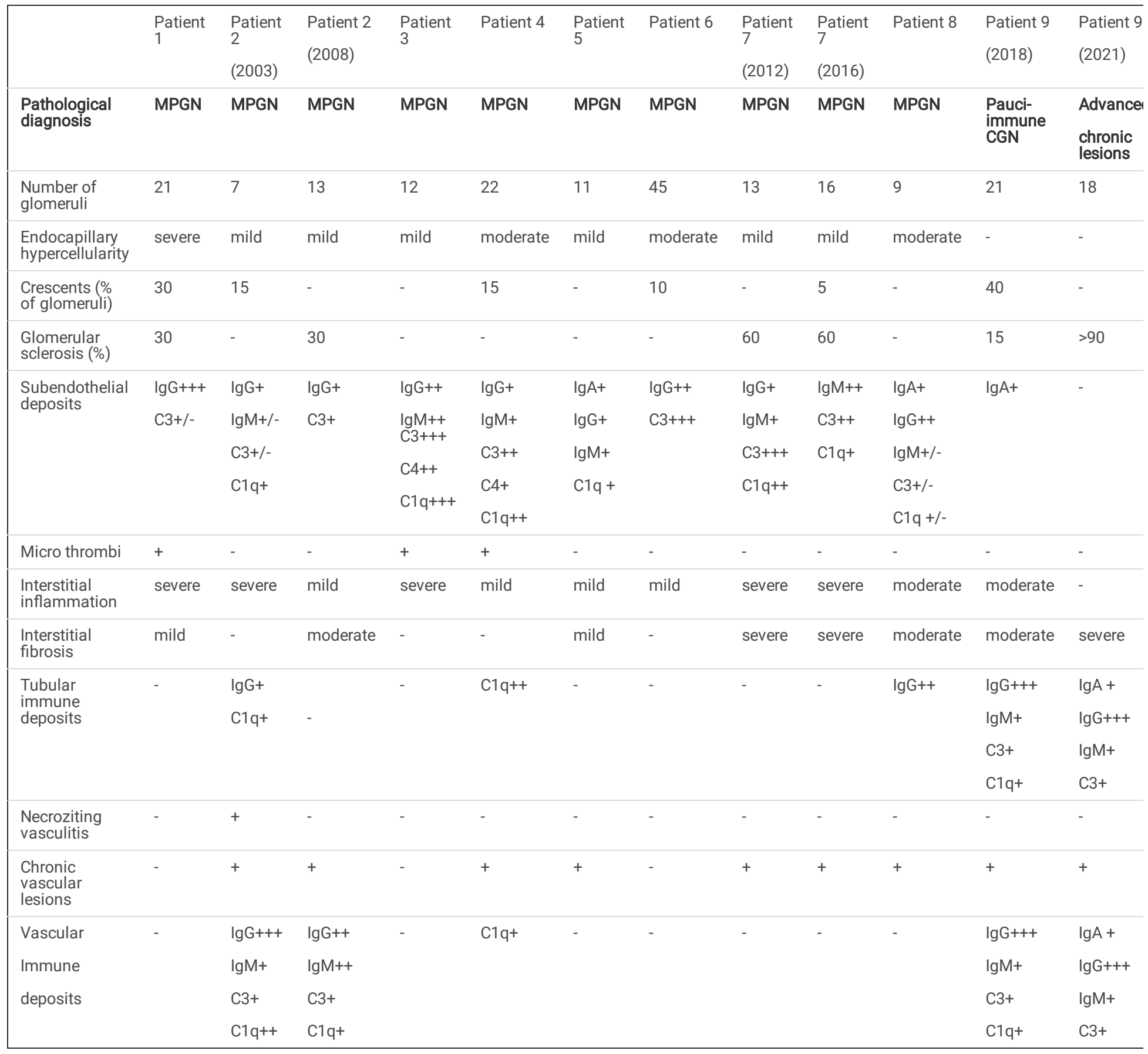

MPGN: membranous and proliferative glomerulonephritis, CGN: crescentic glomerulonephritis, - : negative, +: positive, ++: moderate, +++: abundant

Table 3: Comparison of patients from the present cohort with patients with kidney involvement of HUV from the literature. 


\begin{tabular}{|c|c|c|c|c|}
\hline & Patients report & Litterature review & p & Total \\
\hline Number of patients & 12 & 26 & & 38 \\
\hline Age at diagnosis (years), mean & 42 & 32 & 0.14 & 35 \\
\hline Female gender, $\mathrm{n}(\%)$ & $9(75 \%)$ & $16(61 \%)$ & 0.49 & $25(66 \%)$ \\
\hline \multicolumn{5}{|l|}{ Clinical examination } \\
\hline Asthenia/fever & $10(83 \%)$ & $13(50 \%)$ & 0.07 & $23(60 \%)$ \\
\hline Chronic urticaria & $12(100 \%)$ & $26(100 \%)$ & 1 & $38(100 \%)$ \\
\hline Angioedema/purpura/livedo & $7(58 \%)$ & $13(50 \%)$ & 0.73 & $20(53 \%)$ \\
\hline Cutaneous leucocytoclastic vasculitis & $7 / 9(78 \%)$ & $18 / 18(100 \%)$ & 0.1 & $25 / 27(92 \%)$ \\
\hline Arthralgia/arthritis & $8(67 \%)$ & $13(50 \%)$ & 0.49 & $21(55 \%)$ \\
\hline Anterior uveitis/conjunctivitis & $4(33 \%)$ & $8(30 \%)$ & 1 & $12(32 \%)$ \\
\hline Retinopathy & $2(17 \%)$ & $1(3 \%)$ & 0.23 & $3(8 \%)$ \\
\hline Lymphadenopathy & $5(42 \%)$ & $5(19 \%)$ & 0.23 & $10(26 \%)$ \\
\hline PRESS/peripheral neuropathy & $2(17 \%)$ & $2(7 \%)$ & 0.58 & $4(11 \%)$ \\
\hline Abdominal pain & $1(8 \%)$ & $10(38 \%)$ & 0.12 & $11(29 \%)$ \\
\hline Respiratory disease & $3(25 \%)$ & $5(19 \%)$ & 0.69 & $8(21 \%)$ \\
\hline Cardiac involvement & $1(8 \%)$ & $3(11 \%)$ & 1 & $4(11 \%)$ \\
\hline \multicolumn{5}{|l|}{ Renal presentation : } \\
\hline Proteinuria & $12(100 \%)$ & $22(84 \%)$ & 0.29 & $34(89 \%)$ \\
\hline Nephrotic syndrom & $6(50 \%)$ & $7(26 \%)$ & 0.27 & $13(34 \%)$ \\
\hline Microscopic/macroscopic hematuria & $9(75 \%)$ & $17(65 \%)$ & 0.71 & $26(68 \%)$ \\
\hline Acute kidney injury & $8(67 \%)$ & $10(38 \%)$ & 0.16 & $18(47 \%)$ \\
\hline Hemodialysis at diagnosis & $2(17 \%)$ & $1(3 \%)$ & 0.23 & $3(8 \%)$ \\
\hline High blood pressure & $7(58 \%)$ & $3(11 \%)$ & 0.005 & $9(24 \%)$ \\
\hline \multicolumn{5}{|l|}{ Biology : } \\
\hline Elevated CRP, fibrinogen or ESR & $5(42 \%)$ & $10(38 \%)$ & 1 & $15(39 \%)$ \\
\hline Low C3 & $10(83 \%)$ & $23(88 \%)$ & 0.64 & $32(84 \%)$ \\
\hline Low C4 & $11(92 \%)$ & $21(80 \%)$ & 0.64 & $31(82 \%)$ \\
\hline Low CH50 & $9(75 \%)$ & $14(53 \%)$ & 0.29 & $22(58 \%)$ \\
\hline Low C1q & $7(58 \%)$ & $10(38 \%)$ & 0.31 & $17(45 \%)$ \\
\hline AntiC1q antibody & $8(67 \%)$ & $10(38 \%)$ & 0.16 & $17(45 \%)$ \\
\hline Antinuclear antibody & $7(58 \%)$ & $8(30 \%)$ & 0.16 & $14(37 \%)$ \\
\hline Antiphospholipid antibody & $1(8 \%)$ & $1(3 \%)$ & 0.54 & $2(5 \%)$ \\
\hline Rheumatoid factor & $2(17 \%)$ & $2(7 \%)$ & 0.58 & $4(11 \%)$ \\
\hline Cryoglobulinemia & $5(42 \%)$ & 0 & 0.002 & $3(8 \%)$ \\
\hline ANCA & $6(50 \%)$ & $3(11 \%)$ & 0.02 & $8(21 \%)$ \\
\hline Monoclonal gammopathy & $1(8 \%)$ & 0 & 0.32 & $1(3 \%)$ \\
\hline \multicolumn{5}{|l|}{ Renal biopsy : } \\
\hline Membranoproliferative GN & $8(67 \%)$ & $15(57 \%)$ & 0.73 & $23(61 \%)$ \\
\hline Membranous nephritis & 0 & $3(11 \%)$ & 0.54 & $3(8 \%)$ \\
\hline Lupus like GN (diffuse deposits only) & 0 & $5(19 \%)$ & 0.16 & $5(13 \%)$ \\
\hline Crescentic GN/vasculitis & $3(25 \%)$ & $2(7 \%)$ & 0.30 & $5(13 \%)$ \\
\hline Interstitial nephritis & $1(8 \%)$ & $1(3 \%)$ & 0.54 & $2(5 \%)$ \\
\hline Mean duration of follow up (months) & 107 & 44 & 0.002 & 71 \\
\hline
\end{tabular}




\begin{tabular}{|lllll|} 
Deceased & 0 & $5(19 \%)$ & 0.16 & $5(13 \%)$ \\
\hline End-stage kidney disease & $4(33 \%)$ & $4(15 \%)$ & 0.23 & $8(21 \%)$ \\
\hline Transplantation/Dialysis & $1(8 \%) / 2(17 \%)$ & $1(3 \%) / 3(11 \%)$ & $0.54 / 0.54$ & $2(5 \%) / 5(13 \%)$ \\
\hline eGFR : $15-60 \mathrm{ml} / \mathrm{min} / 1.73 \mathrm{~m} 2$ & $2(17 \%)$ & $3(11 \%)$ & 0.64 & $5(13 \%)$ \\
\hline Persistant proteinuria $(>0.3 \mathrm{~g} / 24 \mathrm{~h}$ or $\mathrm{g} / \mathrm{g})$ & $4(33 \%)$ & $4(15 \%)$ & 0.23 & $8(21 \%)$ \\
\hline
\end{tabular}

PRESS: Posterior reversible encephalopathy syndrome, CRP: C-reactive protein, ESR: elevated sedimentation rate, ANCA: anti-neutrophil cytoplasmic antibodies, GN: glomerulonephritis, eGFR: estimated glomerular filtration rate.

\section{Figures}
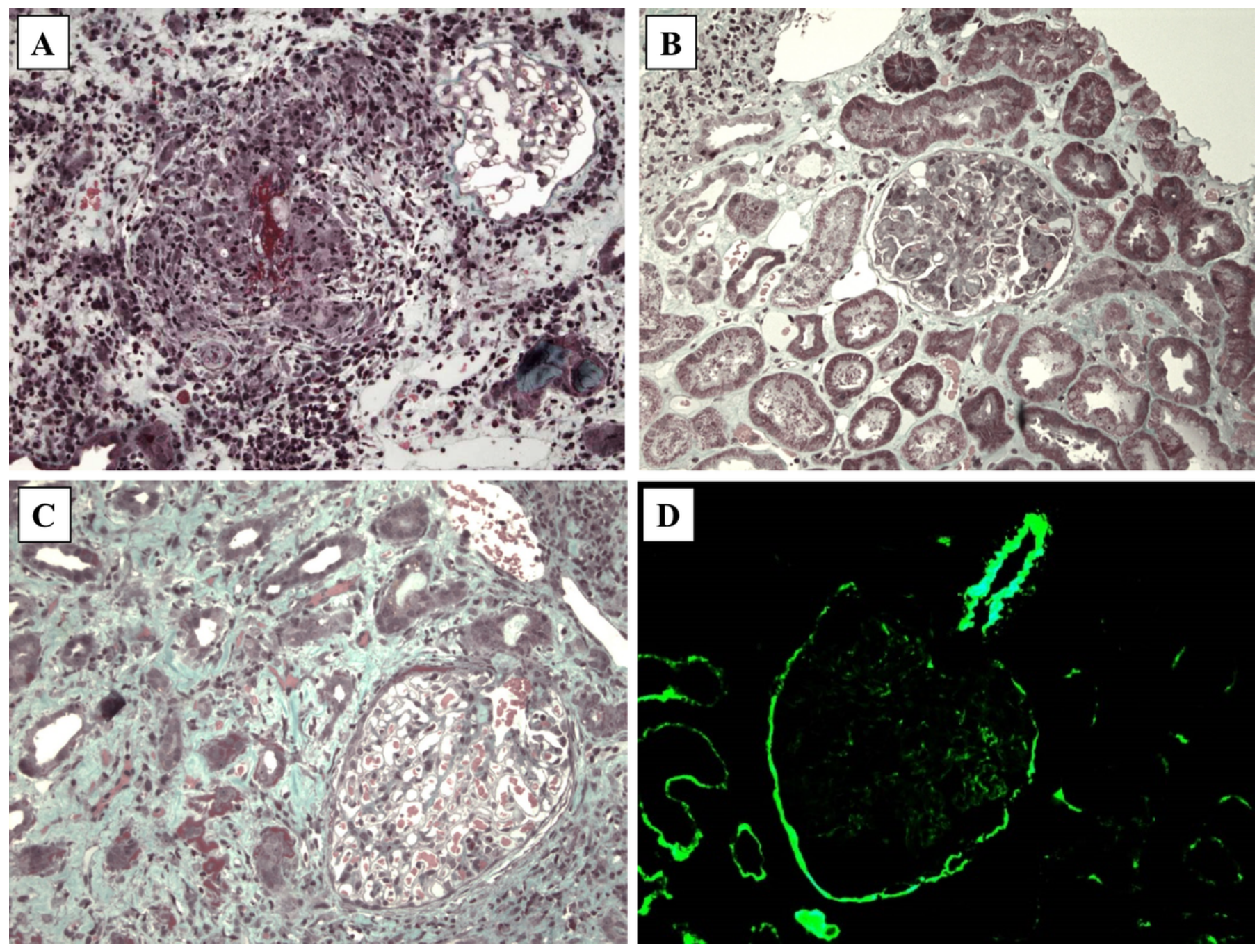

Figure 1

Representative kidney pathological lesions observed in patients with Hypocomplementemic Urticarial Vasculitis from the present cohort. A. Vasculitis with fibrinoid necrosis involving a pre-glomerular arteriole. Masson's trichrome, x 200. B. Global endocapillary proliferation with an interstitium containing a slight peri-venular inflammatory infiltrate. Masson's trichrome, x 200. C. Interstitial nephritis with mononuclear cells, oedema, and suffering tubules. Masson's trichrome, $x$ 200. D. Abundant deposits of C1q within arteriole wall, capsule, and tubular basement membrane. Immunofluorescence, $x 200$ 


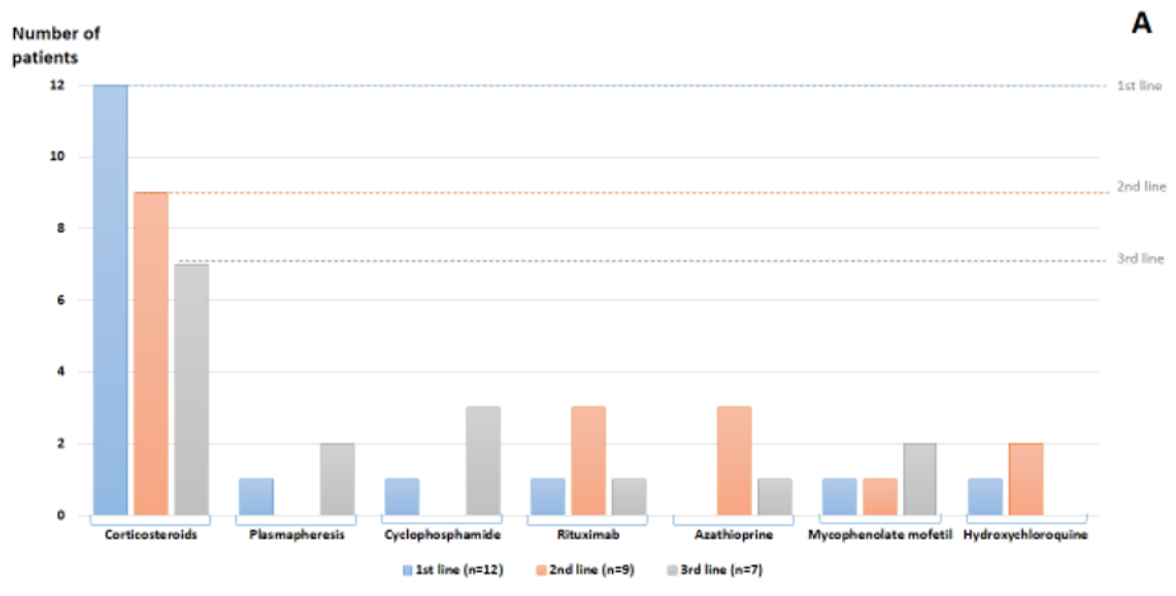

B

Number of

patients

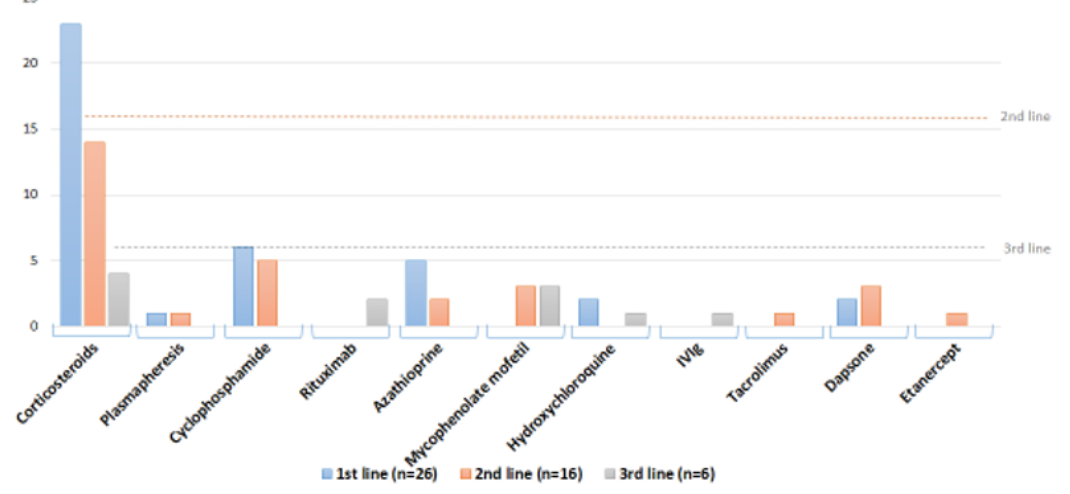

Figure 2

Treatment of the kidney involvement of HUV (first, second and third line therapies) A. In the 12 patients from the present cohort. B. In the 26 patients from the literature. 

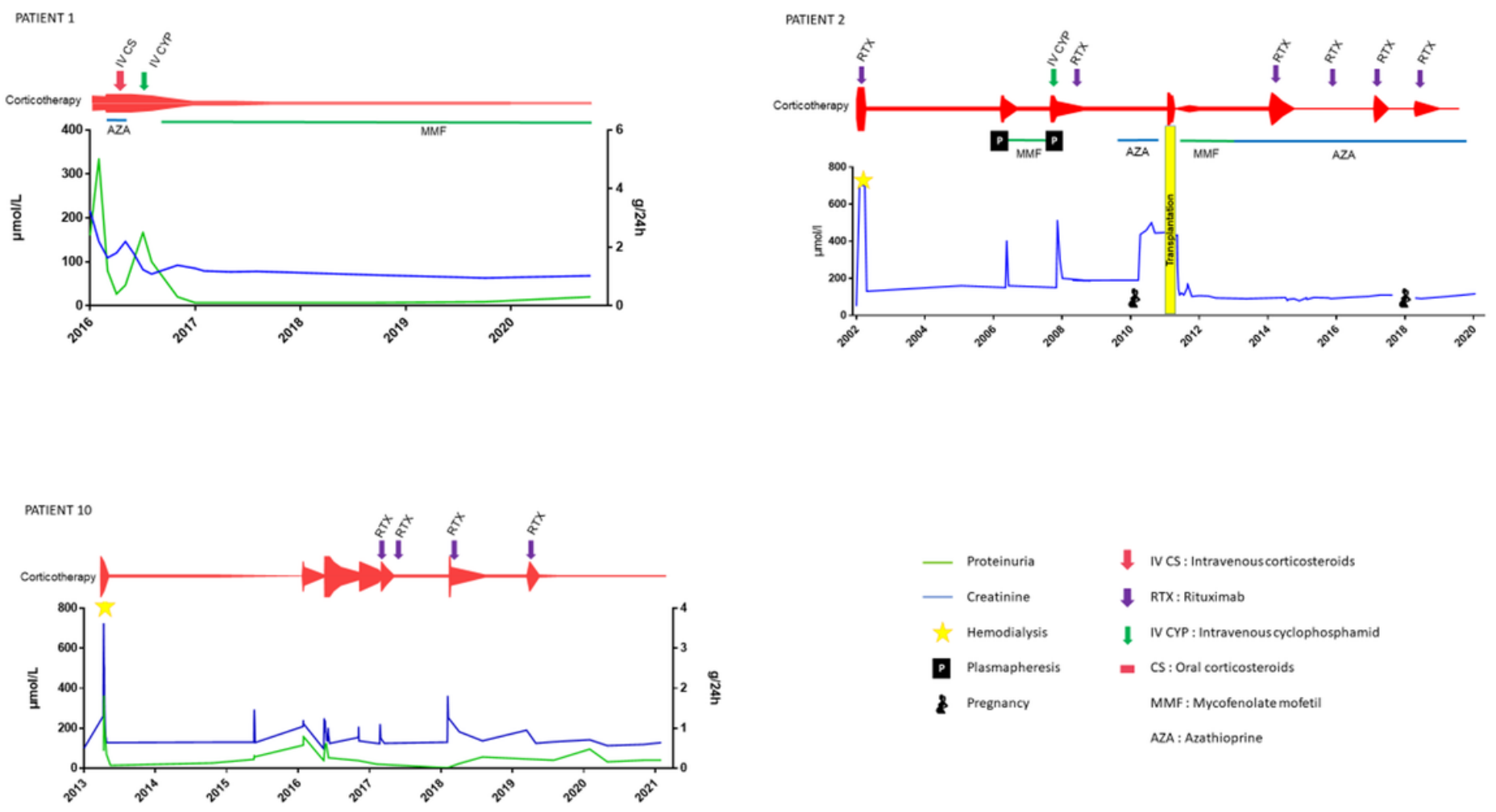

Figure 3

Treatment and renal outcome in 3 patients representative of the present cohort (patients $\# 1, \# 2$ and \#10).

\section{Supplementary Files}

This is a list of supplementary files associated with this preprint. Click to download.

- HUVRenallnvolvementSupplementalFigureS1.pptx 